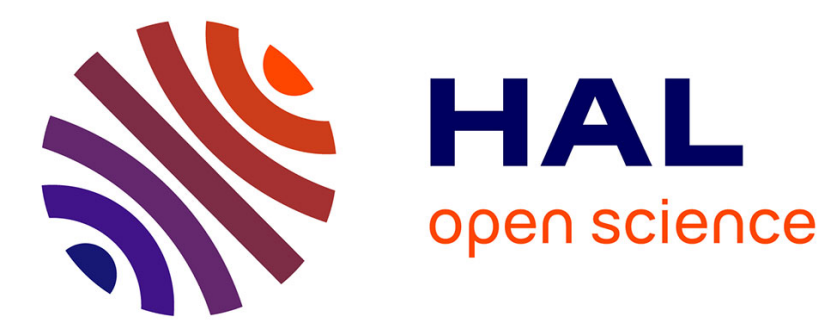

\title{
The ambient noise energy motion in the near-surface layer in ocean wave-guide
}

\author{
V. Shchurov, V. Ilyichev, V. Kuleshov
}

\section{To cite this version:}

V. Shchurov, V. Ilyichev, V. Kuleshov. The ambient noise energy motion in the near-surface layer in ocean wave-guide. Journal de Physique IV Proceedings, 1994, 04 (C5), pp.C5-1273-C5-1276. 10.1051/jp4:19945282 . jpa-00252994

\section{HAL Id: jpa-00252994 https://hal.science/jpa-00252994}

Submitted on 1 Jan 1994

HAL is a multi-disciplinary open access archive for the deposit and dissemination of scientific research documents, whether they are published or not. The documents may come from teaching and research institutions in France or abroad, or from public or private research centers.
L'archive ouverte pluridisciplinaire HAL, est destinée au dépôt et à la diffusion de documents scientifiques de niveau recherche, publiés ou non, émanant des établissements d'enseignement et de recherche français ou étrangers, des laboratoires publics ou privés. 


\title{
The ambient noise energy motion in the near-surface layer in ocean wave-guide
}

\author{
V.A. SHCHUROV, V.I. ILYICHEV and V.P. KULESHOV
}

Pacific Oceanological Institute, Far Eastern Branch, Russian Academy of Sciences, 43 Baltiyskaya Str., Vladivostok, 690041, Russia

\begin{abstract}
The results of measurements of scalar - vector characteristics of the ambient noise acoustic field in deep ocean areas over the range of $1-800 \mathrm{~Hz}$ are presented. The subject of investigations were the ambient noise energy in the part of the ocean wave-guide that lied between the surface and the underwater sound channel axis lying at the depth of the order of $1200 \mathrm{~m}$. A telemetric drifting autonomous system with combined receivers was used in the investigations. A combined receiver consisted of a scalar receiver (hydrophone) and a vector receiver of three components particle velocity. Our studies revealed that ambient noise energy transport in the vertical plane occurred in three main directions: 1) over the range of $1-12 \mathrm{~Hz}$ it proceeded from the underwater sound channel axis to the ocean surface in the angles range of $0^{\circ}-30^{\circ} ; 2$ ) over the range of $32-141 \mathrm{~Hz}$ it proceeded from the sea surface to the underwater sound channel axis in the angles range of $\left.0^{\circ}-40^{\circ} ; 3\right)$ over the range of 282-800 $\mathrm{Hz}$ noise energy $\mathrm{flux}$ made an angle between $10^{\circ}$ and $30^{\circ}$ with $z$ axis, and its horizontal component coincided with wind wave propagation direction over the range of 447-800 $\mathrm{Hz}$. Over the range of $282-355 \mathrm{~Hz}$ horizontal component of the noise energy flux coincided with ripple direction and over the range of $562-800 \mathrm{~Hz}$ it did with the propagation direction of wind surface waves.
\end{abstract}

\section{I NTRODUCTION}

The results of experimental investigations of scalar-vector characteristics of underwater ambient noise in deep open ocean in the frequency range of $1-800 \mathrm{~Hz}$ are presented here. The investigation technique is based on simultaneous measurements of pressure $P(t)$ and the particle velocity components $v_{x}(t), v_{y}(t), v_{z}(t)$ at a point of the acoustic field and their a subsequent statistical cross-analysis.

We consider two components of intensity vector $I(t)\left\{I(t), I_{y}(t)\right.$, $\left.I_{z}(t)\right\}$ : the horizontal component $I_{x y}(t)=\left(I_{x}^{2}(t)+I_{y}^{2}(t)\right)^{\frac{1}{1} 2}$ and the vertical one $I_{z}(t)$. The azimuth and the polar angles of the energy 
flux density vector (intensity vector) are: $\varphi(t)=\operatorname{arcta}\left(I_{y}(t) / I_{x}(t)\right)$, $\vartheta(t)=\operatorname{arctn}\left(I_{x y}(t) / I_{z}(t)\right)$. Values $\left|I_{x y}(t)\right|,\left|I_{z}(t)\right|$ and angles $\varphi(t)$, $\vartheta(t)$, calculated for some frequency range $\Delta f$ are value and direction characteristics of ambient noise energy flow in the ocean waveguide over the frequency range $\Delta \mathrm{f}$.

As it was stressed previously [1], ambient dynamic energy flow (in the frequency range of $200-800 \mathrm{~Hz}$ ) proceeds in two different directions : vertical one (from sea surface roughness to bottom) and horizontal one, coinciding with the direction of wind surface roughness propagation. In this paper the authors examine the temporal dependencies of $\varphi(t)$ and $\vartheta(t)$ for ambient noise energy flow in different frequency over the range of $1-800 \mathrm{~Hz}$.

The measuring facilities and technique are described in [1].

\section{RESULTS OF INVESTIGATIONS}

The time dependencies of both the azimuth angle $\varphi(t)$ of noise energy flow horizontal component $I_{x y}(t)$ and the polar angle $v(t)$ of flux density vector $\vec{I}(t)$ for eight frequency ranges are shown in Figs. 1,2: 1) $1-5 \mathrm{~Hz}$; 2) $5-12 \mathrm{~Hz}$; 3) $32-64 \mathrm{~Hz}$; 4) $56-112 \mathrm{~Hz}$; 5) $112-141 \mathrm{~Hz}$; 6) $282-355 \mathrm{~Hz}$; 7) $447-562 \mathrm{~Hz}$; 8) $562-800 \mathrm{~Hz}$.

Present the results of noise measurements carried out in the South-Chinese sea. Figs. 1 and 2 show the results obtained in the deployment site at $18^{\circ} 40^{\prime} \mathrm{N}, 115^{\circ} 57^{\prime} \mathrm{E}$ in May,89. Conditions of the experiment are as follows: depth - $3600 \mathrm{~m}$; the underwater sound channel axis lies at a depth of $1200 \mathrm{~m}$; the near-surface sound speed is higher than the near-bottom sound speed; wind speed - $12 \mathrm{~m} / \mathrm{s}$; steady-state surface roughness, swell; wind waves and swell propagation directions differ by not more then $15^{\circ}$; measuring devices are mounted at $500 \mathrm{~m}$ depths; the direction of the combined module axis $x$ coincides with surface wave propagation direction; the combined module axis $z$ is vertical and is directed from surface to bottom.

For all frequencies the time of averaging was $120 \mathrm{~s}$. As Figs. 1,2 show, there are three general directions of ambient noise energy flows in both vertical and horizontal plates. Frequency ranges, corresponding to each direction are: a) 1-12 $\mathrm{Hz}$; b) $32-141 \mathrm{~Hz}$; c) $282-800 \mathrm{~Hz}$.

The polar angles $\vartheta(t)$ for each group are well defined. Noise energy flow in the frequency range of $1-12 \mathrm{~Hz}(\mathrm{Fig}$. 2) makes an angle between $0^{\circ}$ and $30^{\circ}$ with the horizontal plane (the angles are measured up from the horizontal plane). Thus the noise energy motion direction in the frequency range of $1-12 \mathrm{~Hz}$ in the near-surface layer of the wave-guide makes an angle between $0^{\circ}$ and $30^{\circ}$ with the ocean surface. Consequently acoustic nolse sources in this frequency region are placed either on the ocean bottom or within its thickness.

Noise energy flow in the frequency range of $32-141 \mathrm{~Hz}$ (Fig. 2) makes an angle between $0^{\circ}$ and $40^{\circ}$ with the horizontal plane (the angles are measured down from the horizontal planel. Hence, the resulting noise energy flow is in the near surface layer of the wave guide and is headed to the underwater noise channel axis. It is well known that the distant navigation is the noise source in this frequency range.

Nolse energy flow vector in the frequency range of $282-800 \mathrm{~Hz}$ makes an angle between $0^{0}$ and $30^{\circ}$ with $z$ axis laccording to the extent of surface roughness) as Fig. 2 illustrates. It is well known that the dynamic processes occurring in the near-surface ocean layer are the main noise sources in the frequency range of $200-800 \mathrm{~Hz}$. Our investigations show that the noise energy flow vector in the 


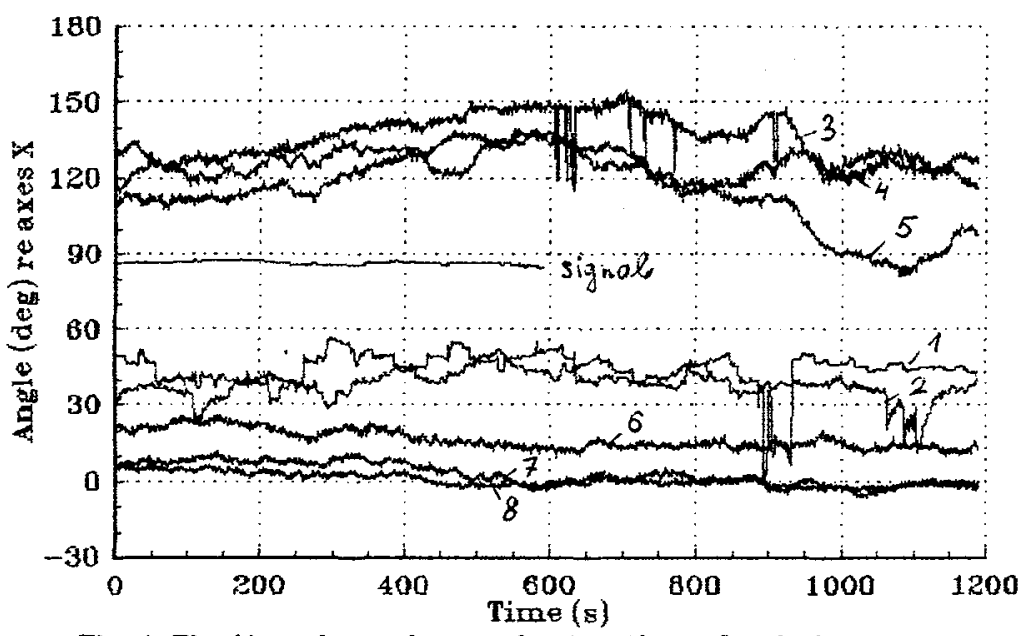

Fig. 1. The time dependence of azimuth angle $\varphi$ of the noise energy flux vector in the eight frequency ranges. Wind speed is $12 \mathrm{~m} / \mathrm{s}$. Experimental depth is $500 \mathrm{~m}$. Exponent averaging time is. $120 \mathrm{~s}$. The designations of the frequency ranges are in the text.

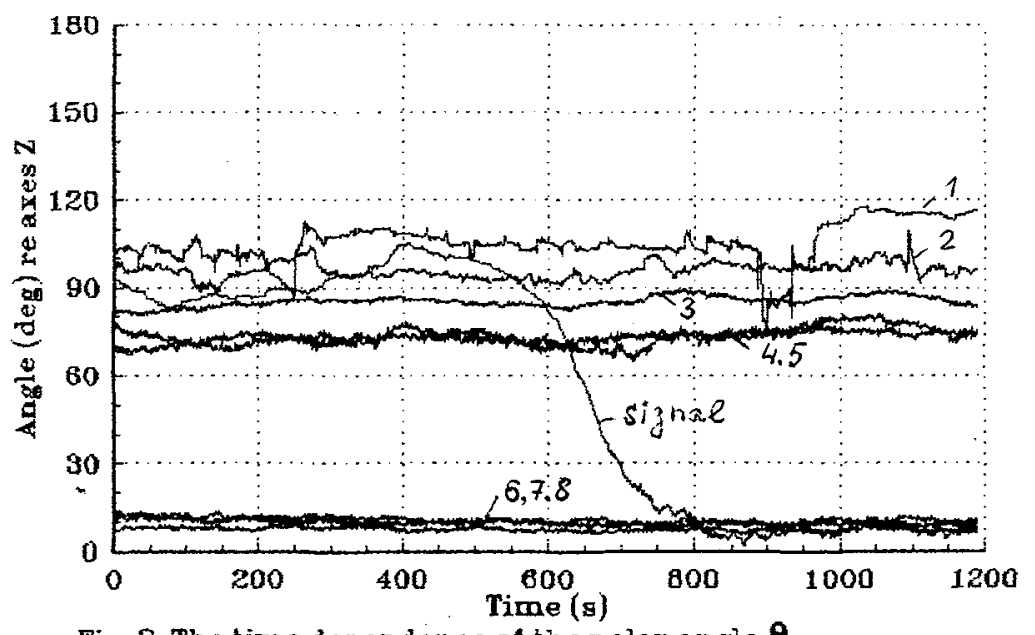

Fig. 2. The time dependence of the polar angle $\theta$ of the noise energy flux vector (corresponding to Fig.1). 
frequency range of $282-800 \mathrm{~Hz}$ makes an angle between $0^{\circ}$ and $30^{\circ}$ with $z$ axis (according to the extent of surface roughness), that is, the acoustic noise energy in this frequency range is transported from the surface roughness to the bottom. In this frequency ranges the direction of the energy $I_{x y}(t)$ horizontal component as is shown in

[1] coincides with the surface wind roughness propagation direction (wind direction). In the frequency ranges of 447-562 Hz and 562-800 $\mathrm{Hz}$ the directions of energy transports in the horizontal plane differ not more than $10^{\circ}$ as Fig. 1 illustrates. Energy transports proceed inside the angle between $0^{\circ}$ and $10^{\circ}$, that is, in directions close to the $x$ axis coinciding with wind speed direction. In the frequency range of $282-355 \mathrm{~Hz}$ energy transport coincides with ripple direction. Fig. 1 illustrates the situation when the angle between wind wave direction and ripple direction is in range $10^{6}-15^{6}$. As expected in the papers $[2,3]$ re-scattering of the initial acoustic field from the surface roughness is the mechanism of horizontal noise energy flow generation. It is supposed, the character of the initial acoustic field re-scattering in the wind wave propagation direction ("forward") differs from the one in the opposite to the wind wave propagation direction ("backward"). The horizontal energy flow value is 0.01-0.1 of the total noise energy flow value (in accordance with the extent of surface roughness, indicating slight differences between mechanisms re-scattering from the surface roughness in the "forward" direction and the "backward" one.

The time dependence of the azimuth and polar angles of signal energy flow (signal frequency is $404 \mathrm{~Hz}$ ) are shown in Figs. 1,2. In the pressure spectrum the signal exceeding over the noise is equal to 8-10 dB, in the cross spectrum it is not more then $18 \mathrm{~dB}$. As lllustrated in Fig.1, the azimuth angle value remains constant, that is, the acoustic measuring module is motionless in the course of observation. The signal is shut down when $t=600 \mathrm{~s}$. In Fig. 1 the azimuth angle of $404 \mathrm{~Hz}$ signal is not exhibited after $t=600 \mathrm{~s}$.

\section{REFERENCES}

1. V.A.Shchurov, "Coherent and diffusive fields of underwater acoustic ambient noise", J.Accost.Soc.Am. Vol.90, No.2, Pt. 1, August 1991, pp. 991-1001.

2 V.A.Shchurov, "Ambient noise energy motion in the near-surface ocean layer", Recent Advances in Underwater Acoustics, Proc.I.O.A. Vol 13, Part 3 (1991), Weymouth, UK, pp. 250-256.

3. V.Shchurov, V.llyichev, and Yu. Khvorostov "Ambient noise anisotropy in horizontal plane", Proc. ICA-14, E1-10, (1992), Beijing, China. 